\title{
Cfd Analysis of Air Swirl in Cylinder of Ci Engine by Modification of Cylinder Head
}

Mahesh G, Hiregoudar Yerrennagoudar, Somanath Swamy R H M

Abstract: Work is based on the impact of air swirl in the cylinder chamber by cfd analysis of a one cylinder $4 \mathrm{~s}$ CI engine is presented. So as to accomplish the swirl, tumble and kinetic energy intensities in the combustion chamber. The cylinder head is modified to increase the turbulence in the chamber. This increases the air motion, is done by removing material and protrusion on the cylinder head. Depending upon on the design configurations of Diesel engine i.e. in the order to exaggerate the air motion and to provide homogenous mixture in the cylinder and its effects on the emission and performance.

Keywords: CI engine head modification, Combustion chamber and performance.

\section{INTRODUCTION}

In generally all automobile parts will have an analysis, researcher are trying to create flow pattern on standard flow. Two types of flow in the cylinder, flow on cylinder axis and tumble flow in diesel engines. Air flow types, on the basis of cylinder axis to flow will be different motion. In the case of swirl flow, the air flow axis is parallel to axis of the cylinder. Performance of CI engine will increases with Air flow entering into the Combustion chamber and have ability of controlling the air-fuel mixture in CI engines. Combustion, emission and performance parameters depend upon the mixture of Air-fuel. Air flow in the cylinder is depending on the inlet manifold, profile of valves and CC geometry.

\section{LITERATURE SURVEY}

Jinou Song et al [1] have conducted an experiment based on the different CC geometry used in cylinder DI engine and calculated the three-dimensional flow. Bowl type pistons are used to find the determinant factors for the growth and formation of the flow field in cylinder. Piston geometry plays very important role to have swirl ratio on profiles and vital impact on the distribution at the cross section.

Revised Manuscript Received on April 02, 2020.

* Correspondence Author

Mahesh G*, Assistant Professor, Department of Mechanical Engineering, Rao Bahadur Y Mahabaleshwarappa Engineering College, Ballari, Karnataka

Dr. Hiregoudar Yerrennagoudar, Professor, Department of Mechanical Engineering, Rao Bahadur Y Mahabaleshwarappa Engineering College, Ballari, Karnataka

Somanath Swamy R H M, Assistant Professor, Department of Mechanical Engineering, Rao Bahadur Y Mahabaleshwarappa Engineering College, Ballari, Karnataka

(C) The Authors. Published by Blue Eyes Intelligence Engineering and Sciences Publication (BEIESP). This is an open access article under the CC BY-NC-ND license (http://creativecommons.org/licenses/by-nc-nd/4.0/)
Gyeung Ho Choi et al [2] have conducted an experimental analysis on swirl chamber effects on the characteristics of combustion in CI engine. It depends upon the geometry of hole , angle of inclination and area occupied by the jet spray. Due to interblend, effect on the parameters of CI engine varies which helps to influence for the generation of TKE.

Pavlos Dimitriou et al [3] have conducted an experimental analysis on angle of jet spray and various geometries of the piston are used to analyze the quality of fuel air mixture and compared with the quantitative measuring factors on CI engine. A higher swirl value is obtained in the cylinder which helps to increase of fuel air mixture. The best output value is obtained with the piston having narrow entry and steep combustion chamber.

\section{METHODOLOGY}

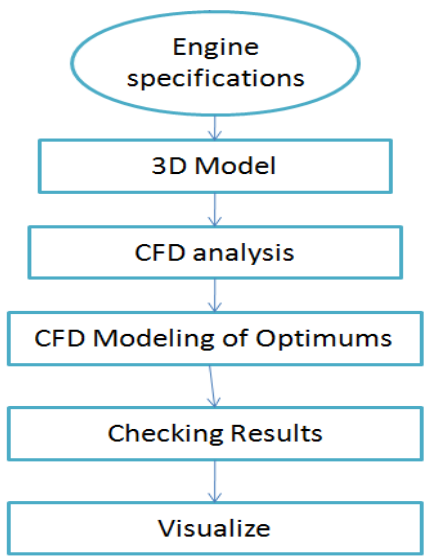

\section{EXPERIMENTAL DETAILS}

\begin{tabular}{|l|l|}
\hline \multicolumn{2}{|l|}{ Water cooled, single cylinder, 4-stroke diesel engine } \\
\hline Engine make & Kirloskar \\
\hline Model & TV1 \\
\hline Power & $5.2 \mathrm{KW}$ \\
\hline Bore Diameter & $87.5 \mathrm{~mm}$ \\
\hline Stroke length & $110 \mathrm{~mm}$ \\
\hline Speed & $1500 \mathrm{rpm}$ \\
\hline Compression ratio & $17.5: 1$ \\
\hline Swept volume & $661.45 \mathrm{cc}$ \\
\hline
\end{tabular}




\section{3D MODEL DESIGN}

3D model of CI engine head is created based on availability of conventional engine head. By using CATIA V-5 R18 software.

Conventional engine head.

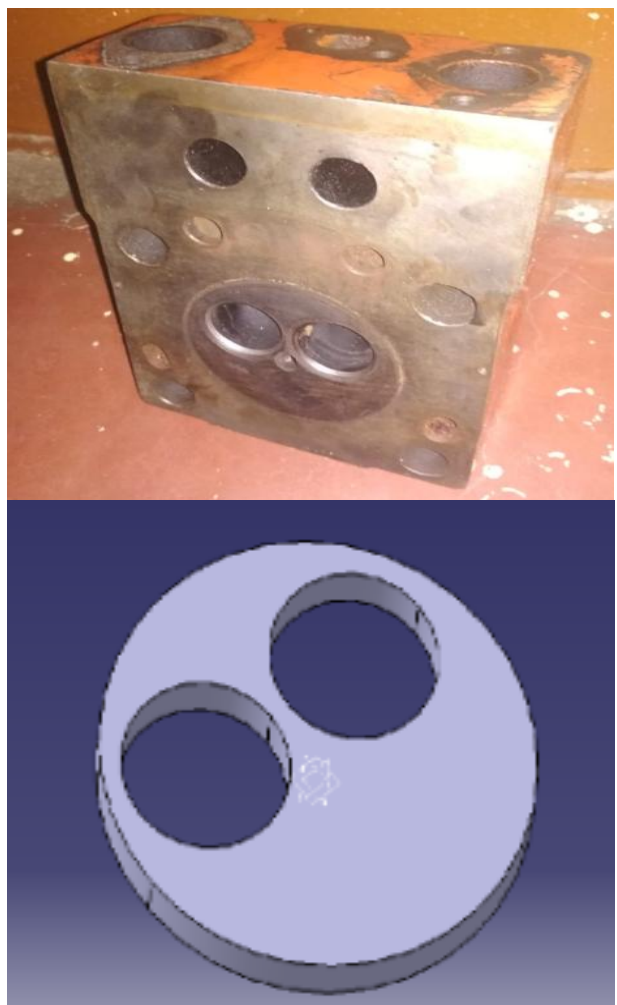

Fig. 1: Conventional engine head.

Modified engine head

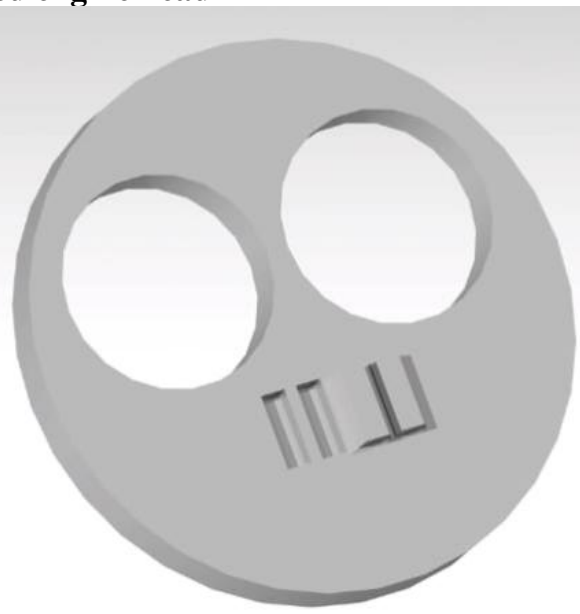

Fig. 2: Modified engine head.

VI. RESULT AND DISCUSSION

Pressure distribution:
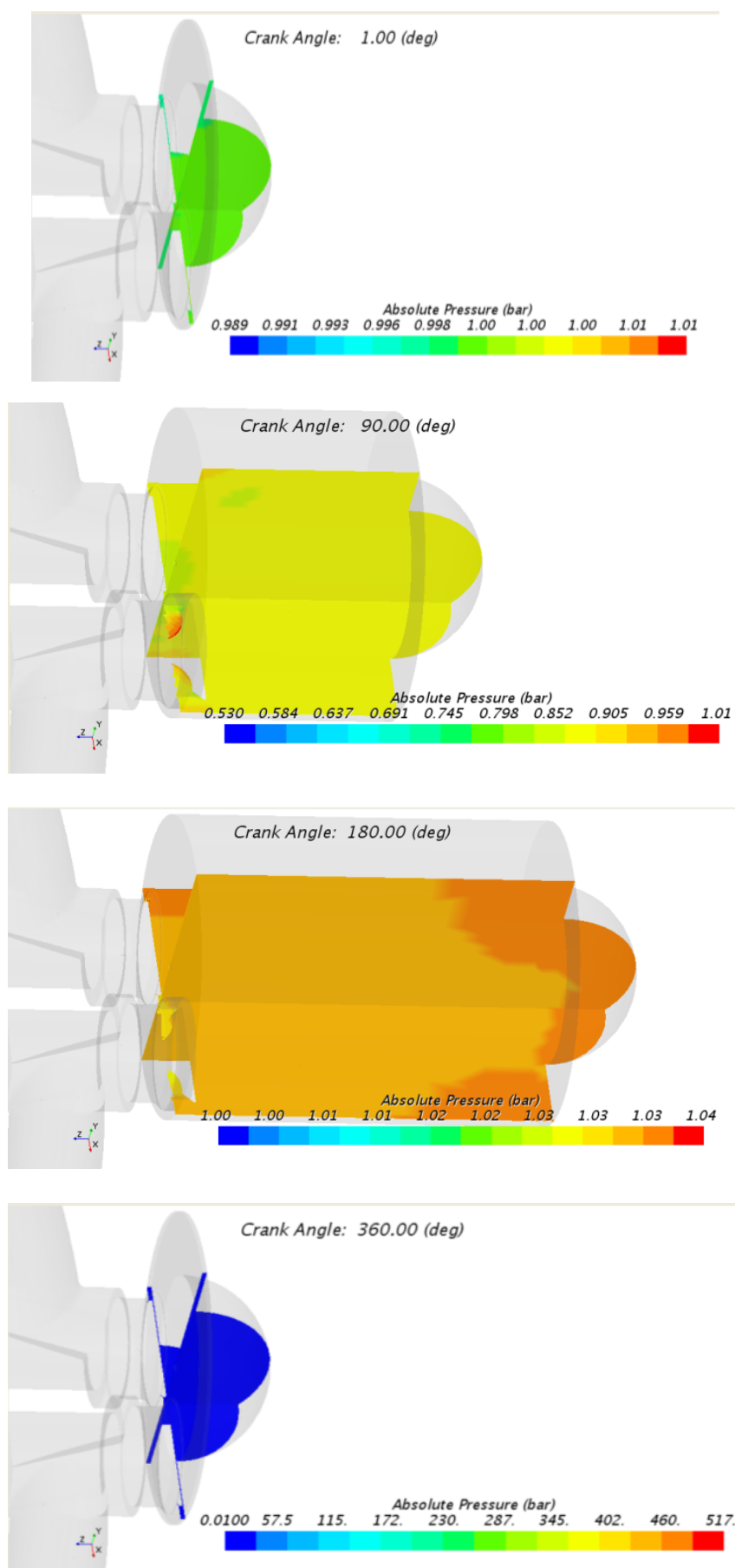

Fig. 3: Pressure distribution for Conventional cylinder head at different angles.

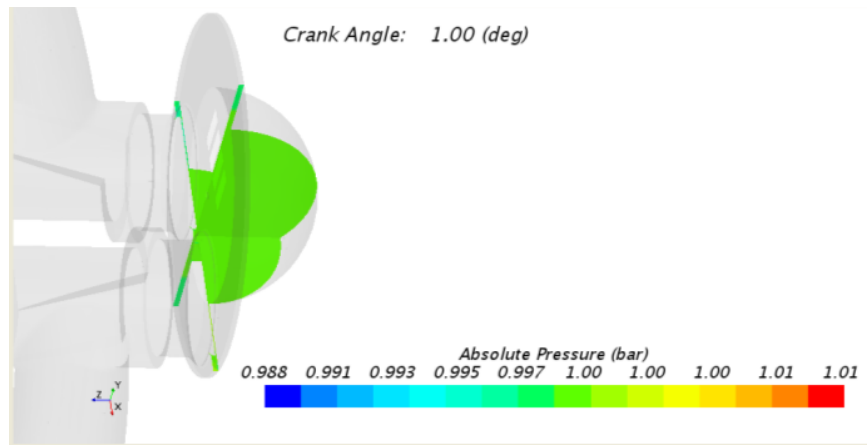

Published By:

Blue Eyes Intelligence Engineering \& Sciences Publication

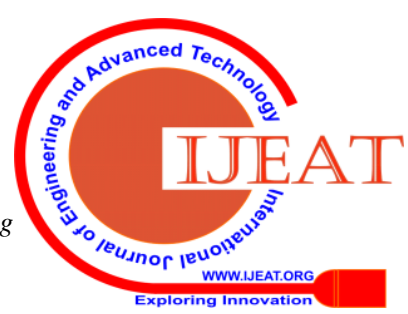



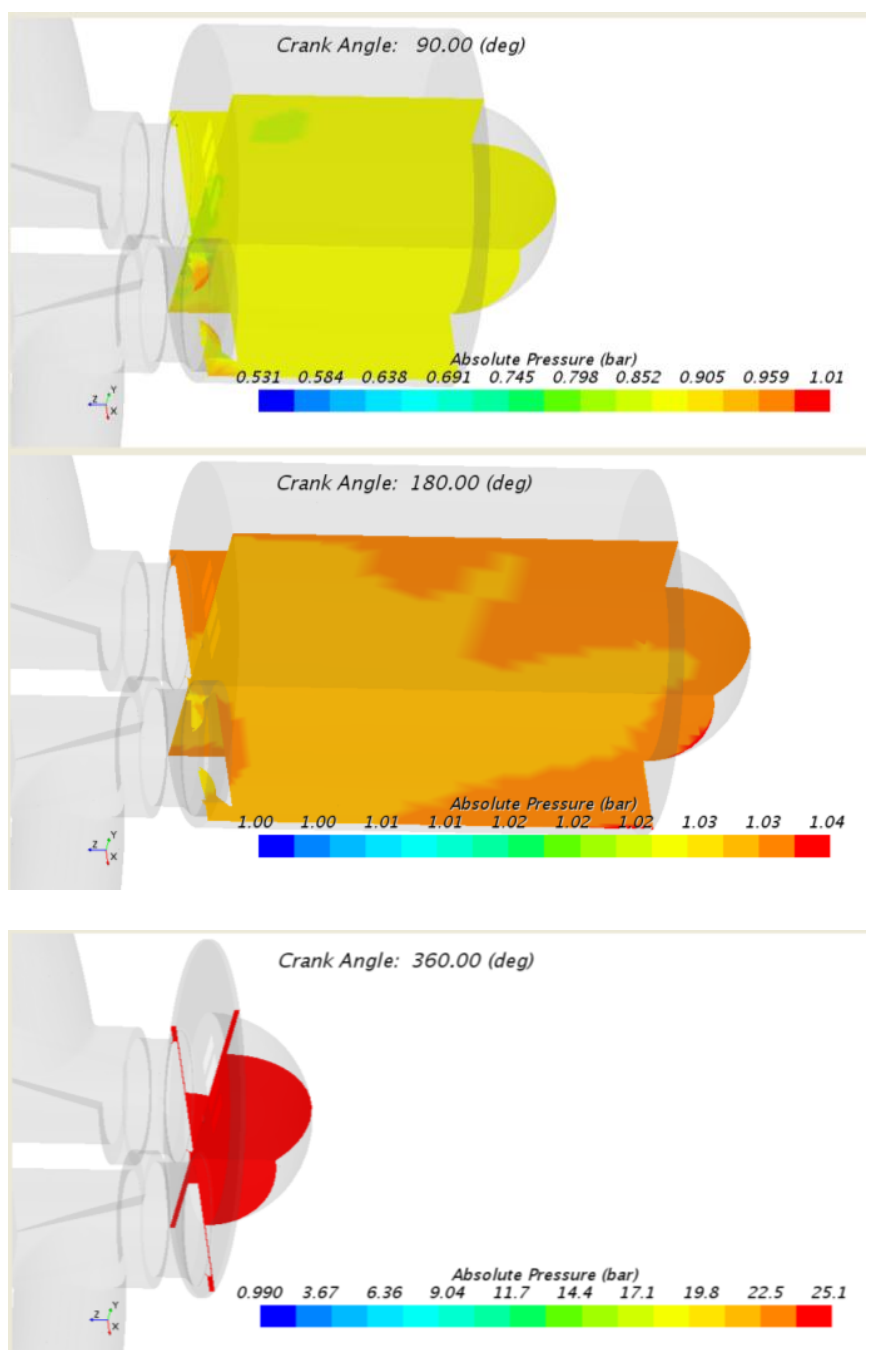

Fig. 4: Pressure distribution for Modified cylinder head Velocity distribution:

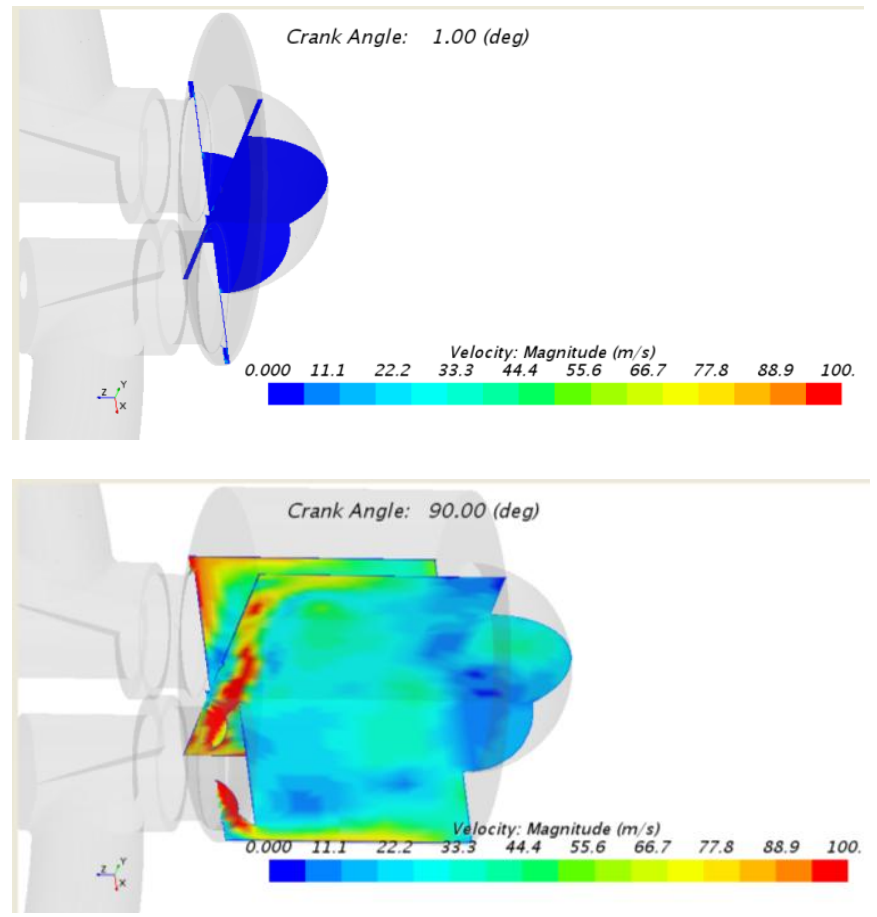

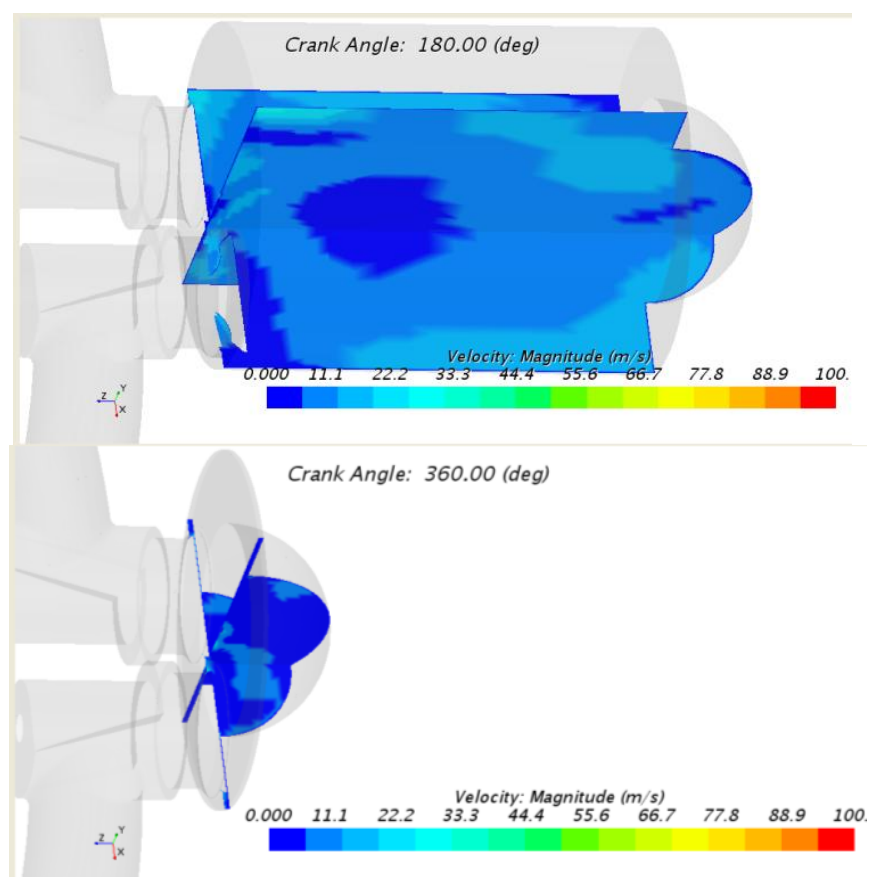

Fig. 5: Velocity distribution for Conventional cylinder head at different angles.
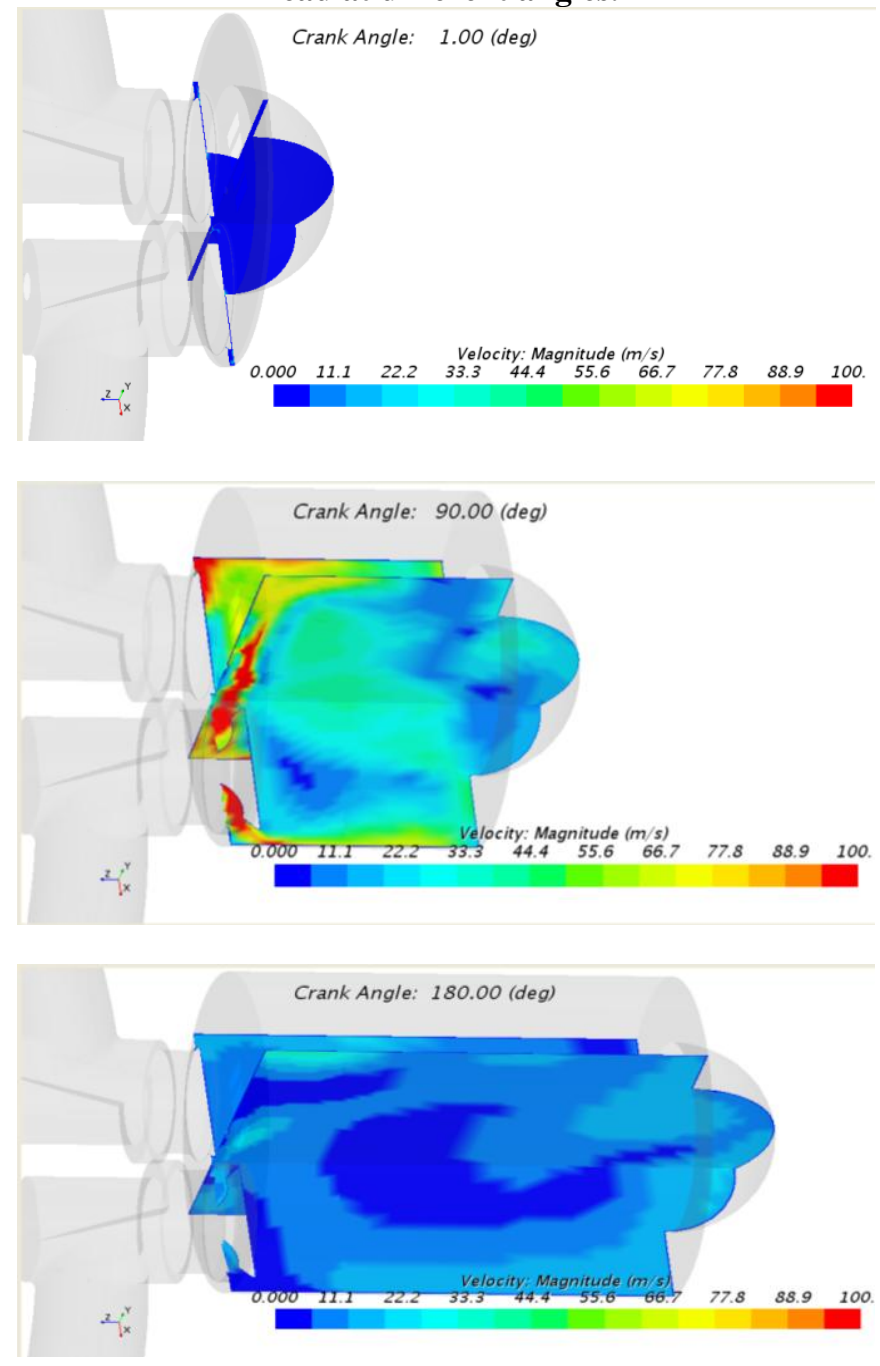

Published By:

Blue Eyes Intelligence Engineering \& Sciences Publication

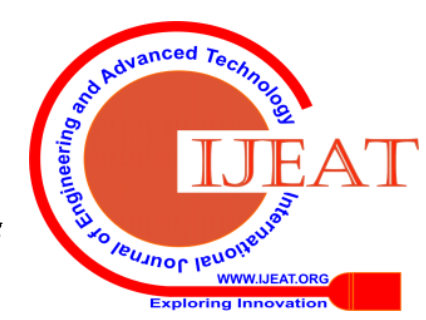




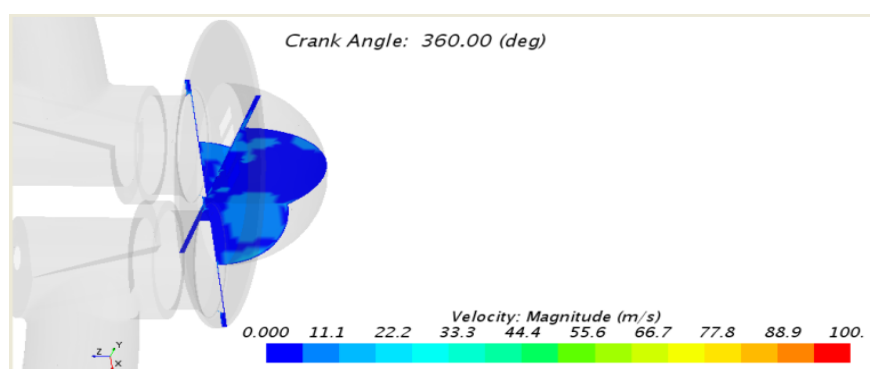

Fig. 6: Velocity distribution for Modified cylinder head at Temperature distribution: different angles.

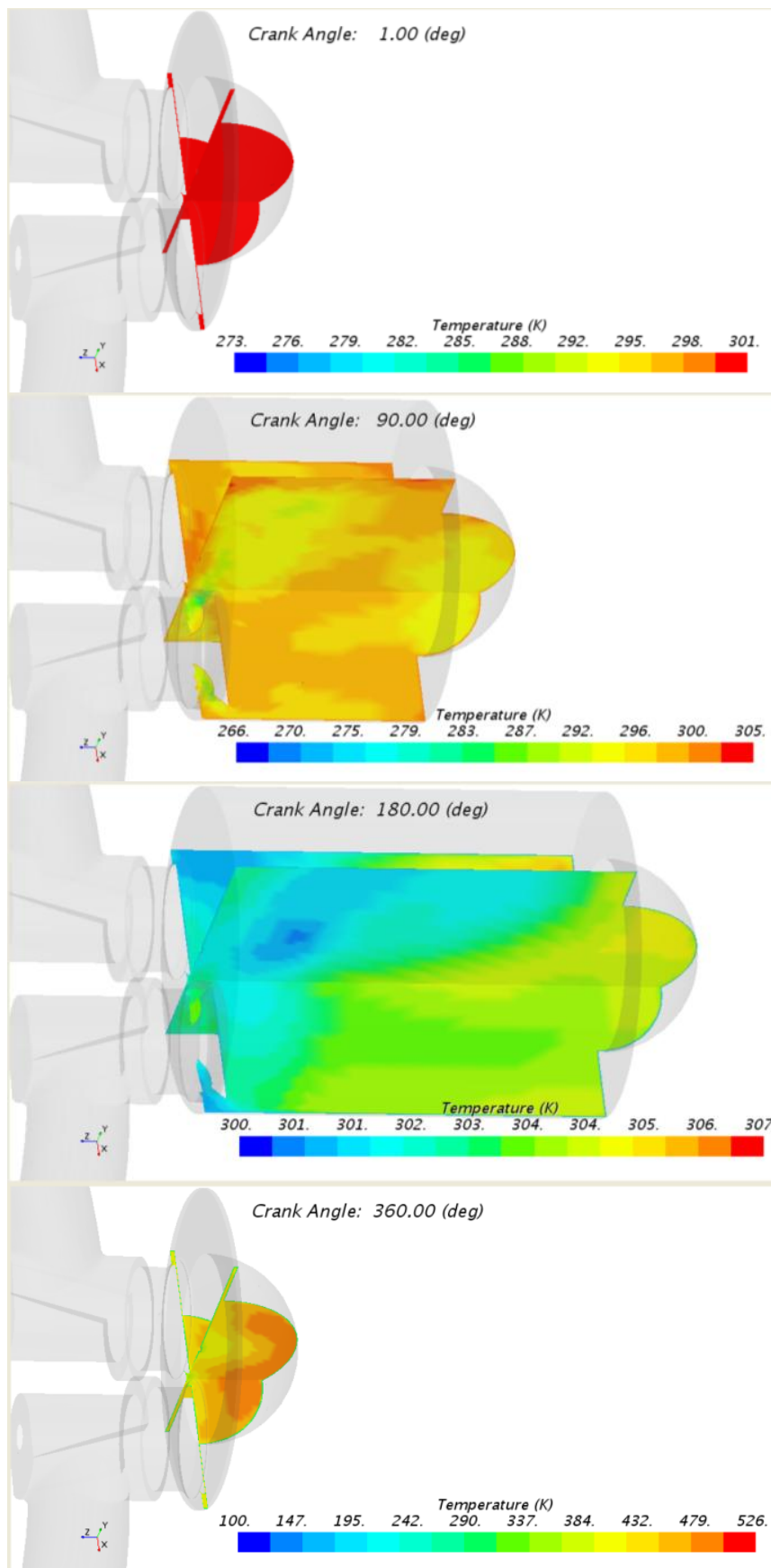

Fig. 7: Temperature distribution for Conventional cylinder head at different angles.
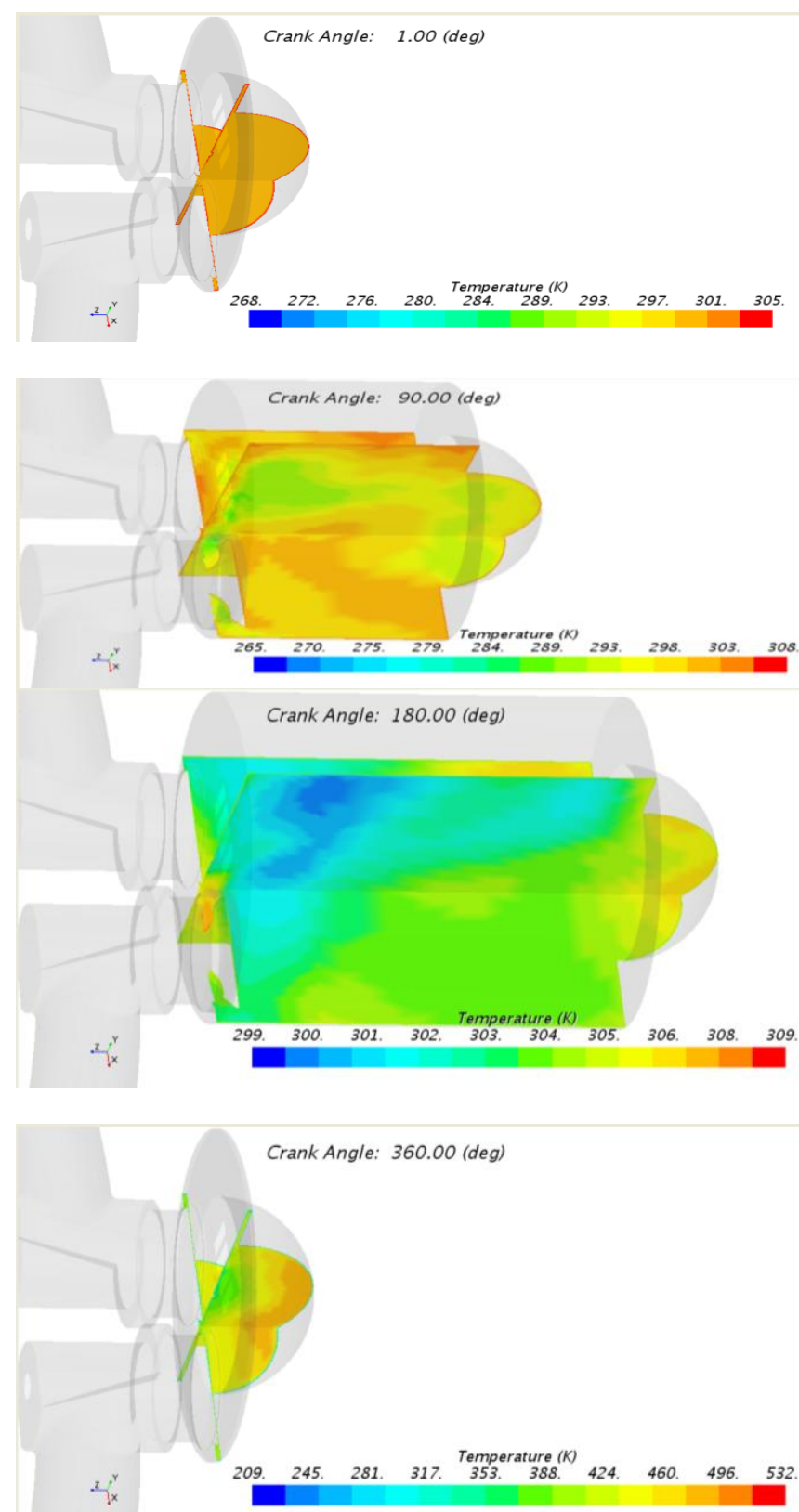

Fig. 8: Temperature distribution for Modified cylinder head at different angles.

Swirl Ratio - X

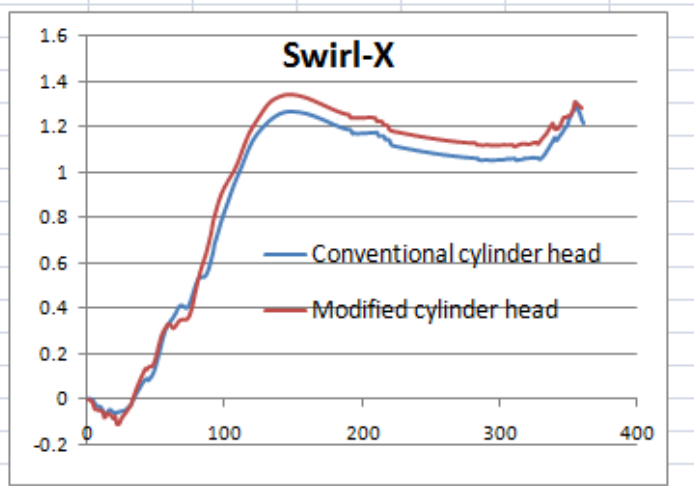

Tumble Ratio - X

Fig. 9: CA v/s Swirl ratio.

Published By:

Blue Eyes Intelligence Engineering \& Sciences Publication

DOI: 10.35940/ijeat.D7050.049420

Journal Website: www.ijeat.org

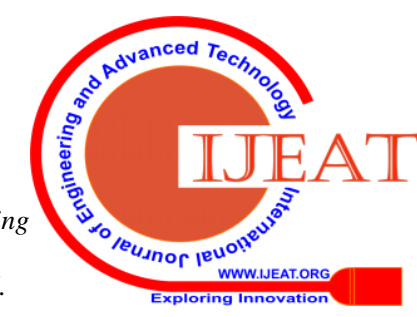




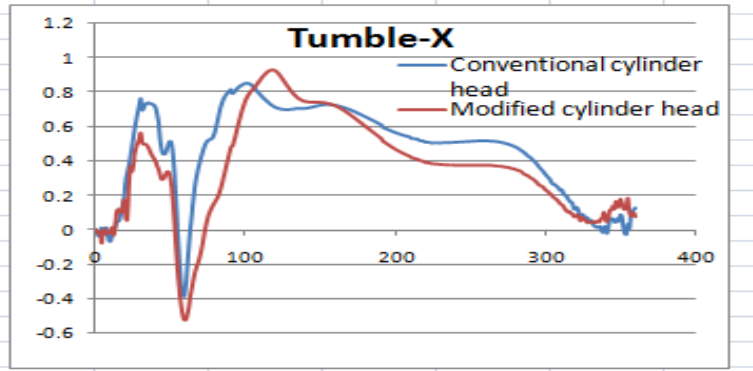

Fig. 10: CA v/s Tumble ratio $-X$.

Tumble Ratio - Y

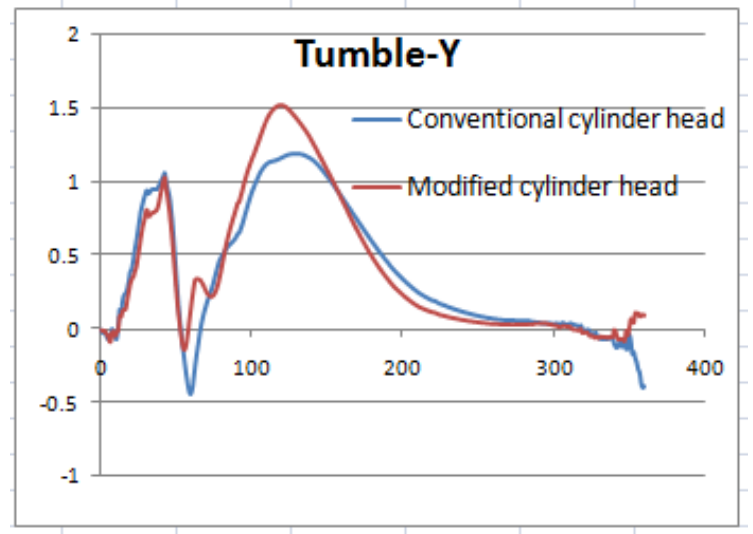

Fig. 11: CA v/s Tumble ratio -Y.

Turbulence kinetic energy

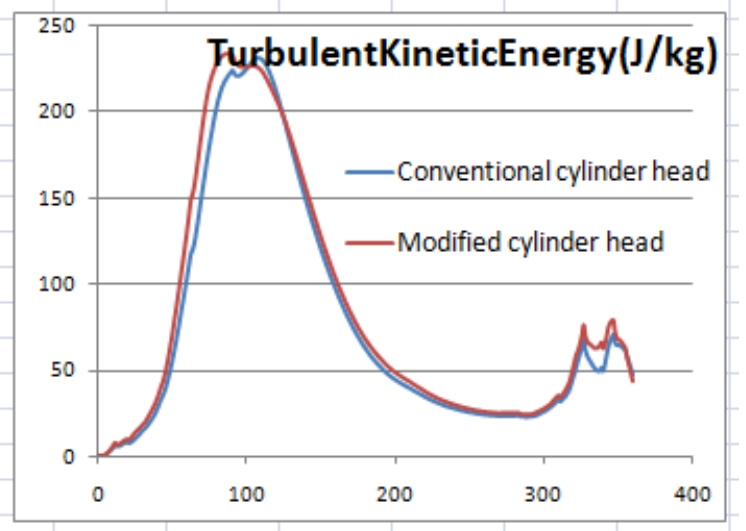

Fig. 12: Crank angle v/s Turbulence kinetic energy.

\section{CONCLUSION}

1. Swirl X-axis: Swirl in modified cylinder head is exhibiting a improvement as compared to conventional cylinder head.

2. Tumble X-axis: Tumble in modified cylinder head is improved as compared to conventional cylinder head at an angle more than $100^{\circ}$ and $300^{\circ}$.

3. Tumble Y-axis: Tumble in modified cylinder head is improved as compared to conventional cylinder head at an angle more than $100^{\circ}$ and $320^{\circ}$.

4. Turbulence Kinetic Energy: Turbulence Kinetic Energy in modified cylinder head is improved as compared to conventional cylinder head at an angle less than $100^{\circ}$ and more than $180^{\circ}$.

5. Pressure distribution for Modified cylinder head is increased at an angle at 1800 compared to conventional cylinder head.

\section{REFERENCES}

Retrieval Number: D7050049420/2020CBEIESP DOI: 10.35940/ijeat.D7050.049420
1. Jinou Song1, Chunde Yao2, Yike Liu3 and Zejun Jiang4, "Investigation on flow field in simplified piston bowls for di diesel engine" State Key Laboratory of Engines, Tianjin University, Tianjin 300072, China. Engineering Applications of Computational Fluid Mechanics Vol. 2, No. 3, pp. 354-365 (2008).

2. Gyeung Ho Choi1, Jae Cheon Lee2, Tae Yun Kwon3 "Combustion characteristics of a swirl chamber type diesel engine" 1 EROOM G \& G Co., Ltd., 83-1 Nakha-ri, Tanhyeon-myeon, Paju-si, Gyeonggi-do, 413-843, Korea, 2 Department of Mechanical \& Automotive Engineering, Keimyung University, Daegu, 704-701, Korea, 3 Graduate School of Automotive Engineering, Keimyung University, Daegu, 704-701, Korea. Journal of Mechanical Science and Technology 23 (2009) 3385 3392,DOI10.1007/s12206-009-1011-2, August 9, 2009.

3. Pavlos Dimitriou1, Weiji Wang1 and Zhijun Peng2 "A piston geometry and nozzle spray angle investigation in a DI diesel engine by quantifying the air-fuel mixture" 1School of Engineering \& Informatics, University of Sussex, Brighton, BN1 9QT, UK International journal of spray and combustion dynamics Volume $\cdot 7$. Number $\cdot 1$ - pages 1 - 24, August 16, 2014.

4. P.Venkatesh1, G. Anand Rao2, "Reduction of emissions by changing piston geometry" Department of MECH, MLR institute of technology, Ranga Reddy, Telangana, India. International journal of professional engineering studies, Volume VI /Issue 2 / DEC 2015.

5. Praveen A. Harari1, S. S. Ghadg2, Arun Pattanashetti3 “A Review on Effect of Combustion Chamber Geometry on the Performance Combustion and Emission Parameters of Compression Ignition Engine Fuelled with Biodiesel" Department of Mechanical Engineering, SGOICOE, Belhe (Pune), Maharashtra, India. International Journal of Engineering and Management Research, Volume-6, Issue-3, May-June 2016, Page Number: 304-316

\section{AUTHORS PROFILE}

Mahesh G, Working as Assistant Professor in the Department of Mechanical Engineering, Rao Bahadur Y Mahabaleshwarappa Engineering College, Ballari, Karnataka has Teaching Experience of 8 years. Area of Research is IC Engines. He is member of MISTE, SESI.

Email: Mahesh.rymec477@gmail.com

Dr. Hiregoudar Yerrennagoudar, Working as Professor in the Department of Mechanical Engineering, Rao Bahadur Y Mahabaleshwarappa Engineering College, Ballari, Karnataka has pursued his Ph.D from JNTU and has carried out more than 10 research projects sponsored by AICTE-New Delhi and KSCST. He has published more than 120 International journals under his name and visited Boston, Yale \& Texas University for invited talks.

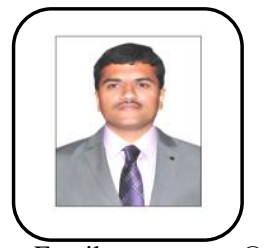

Somanath Swamy R H M, Working as Assistant Professor in the Department of Mechanical Engineering, Rao Bahadur Y Mahabaleshwarappa Engineering College, Ballari, Karnataka has Teaching Experience of 8 years and Research experience of 5 years. Area of Research is IC Engines and Fluid Flow and he is member of MISTE.

Email: somswamy@gmail.com

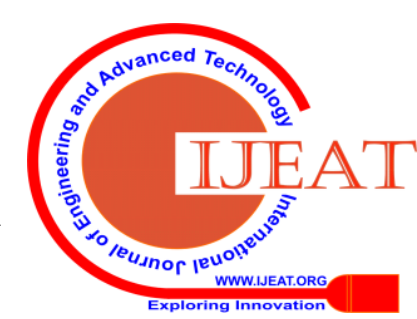

